\title{
Current directions, conceptions and viewpoints on 2019-nCoV (Review)
}

\author{
XIAO FENG ${ }^{1}$, XIAOYU XIE ${ }^{2}$, SHOUYANG SONG ${ }^{2}$, WENJUN CHEN ${ }^{2,3}$, HONGJUN BIAN $^{4}$, \\ FAJUAN RUI ${ }^{1}$, QIANG ZHU ${ }^{1,2}$, WANHUA REN ${ }^{5}$, CHENGYONG QIN ${ }^{1,2}$ and JIANNI QI ${ }^{6,7}$

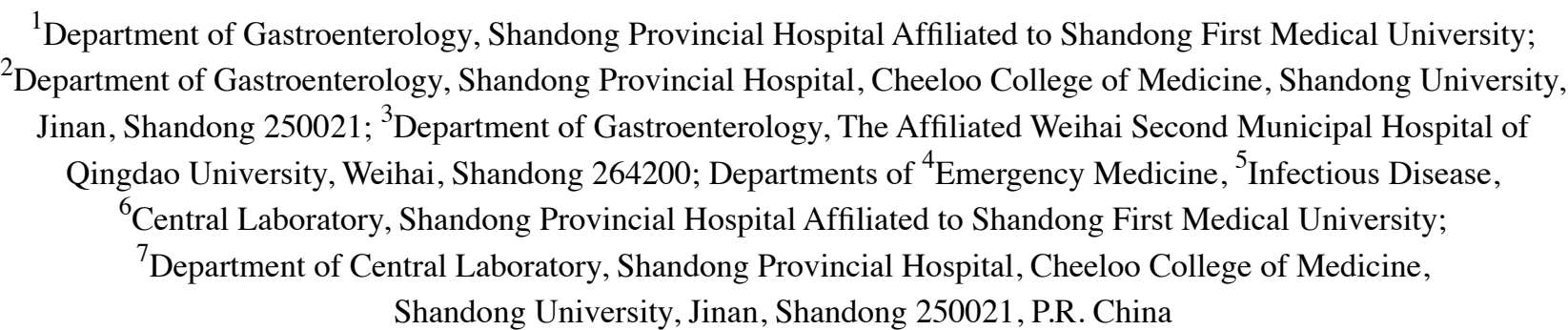

Received April 27, 2020; Accepted October 30, 2020

DOI: $10.3892 /$ etm.2020.9502

\begin{abstract}
On December 31, 2019, the first case of a novel coronavirus infection was reported in Wuhan, China. The ongoing outbreak of the 2019 novel coronavirus (2019-nCoV) has caused immense global concern. According to the recommendations of the International Health Regulations Emergency Committee and the facts and cases that 215 other countries have also reported to date, the World Health Organization Director-General announced that the outbreak of 2019-nCoV constitutes a public health emergency of international concern and a severe threat to the human health worldwide. To date, the prevalence of the virus has continued in waves and is increasing globally. The present review briefly introduces the epidemiology of 2019-nCoV, as well as viral structural characteristics, and receptors and cells that may act after entering the body, laboratory examinations, imaging and pathological features, clinical manifestations, complications, treatment and management.
\end{abstract}

\section{Contents}

1. Introduction

2. Epidemiology of coronavirus disease 2019 (COVID-19)

3. Structural characteristics and possible binding receptors of the 2019 novel coronavirus (2019-nCoV)

Correspondence to: Dr Jianni Qi, Central Laboratory, Shandong Provincial Hospital Affiliated to Shandong First Medical University, 324 Jingwu Road, Jinan, Shandong 250021, P.R. China

E-mail: slqijn@126.com

Key words: 2019 novel coronavirus, epidemiology, structure, receptor, clinical management
4. 2019-nCoV-infected target cells

5. Clinical manifestations and complications of COVID-19

6. Laboratory examinations, imaging and pathological features of COVID-19

7. Treatment of COVID-19

8. Conceptions

9. Conclusions and future prospects

\section{Introduction}

Coronavirus is an enveloped positive-stranded RNA virus, whose gene-encoding contents include a trimer structure spike protein, a homodimeric cysteine proteinase, an RNA polymerase and several nonstructural proteins, belonging to the Coronaviridae and single-stranded virus orders order (Nidovirales); it is widely distributed in humans and other mammals $(1,2)$. Prior to the emergence of $2019-n \mathrm{CoV}$, two other highly pathogenic coronaviruses emerged in the $21 \mathrm{st}$ century, namely the severe acute respiratory syndrome coronavirus (SARS-CoV) and the Middle East respiratory syndrome coronavirus (MERS-CoV) (3). However, the coronaviruses that have been discovered to date may be just the tip of the iceberg, and there may be other novel and more severe animal infectious diseases which will be present in the future (1).

In December 2019, a series of unexplained pneumonia cases were reported in Wuhan, Hubei, China (4). The clinical manifestations of these cases were highly similar to viral pneumonia (5). According to deep sequencing analysis of respiratory tract samples, a novel coronavirus was identified and named as 2019-nCoV (1), which is the seventh member of the coronavirus family that infects humans (4). This is the third coronavirus outbreak in recent years following SARS-CoV and MERS-CoV (6). Pneumonia caused by 2019-nCoV is termed as COVID-19. The virus subsequently spread throughout China and worldwide and poses a global threat to human health. 
The aim of the present review was to summarize and discuss the characteristics of 2019-nCoV, the possible receptors and cells with which it interacts following its entry into the human body, as well as the epidemiology, laboratory examinations, features of imaging and pathology, clinical manifestations, complications, therapy and management of COVID-19. The objective was to provide information regarding the characteristics of 2019-nCoV itself and COVID-19 to improve understanding and response to the virus. The present review also aimed to discuss the necessary means for the rapid control of subsequent outbreaks and for the prompt development of a vaccine.

\section{Epidemiology of COVID-19}

According to data from the National Health Commission of the People's Republic of China, as of November 2, 2020 $>46,800,000$ cases of the virus have been reported worldwide, where $>80,000$ cases have been diagnosed in China $(7,8)$. In addition, $>9,470,000$ cases of COVID-19 have been confirmed in the United States, according to data from the Johns Hopkins website (8). Currently, the United States has the highest number of confirmed 2019-nCoV cases worldwide. This is followed by India, which has $>8,220,000$ cumulative cases $(7,8)$.

Regarding the population most susceptible to COVID-19, middle-aged and elderly patients with underlying chronic diseases, such as hypertension, diabetes, cardiovascular and respiratory diseases, are more likely to become infected, while children and adolescents have a relatively low infection rate, ranging from $0.80-4.0 \%$ (9). Males are slightly more sensitive to COVID-19 and have a poorer prognosis than females due to high expression of angiotensin-converting enzyme 2 (ACE2), smoking and reduced vitamin D production (10-12). In terms of mortality rates, significant differences have also been reported among countries. It has been noted that this mortality rate is particularly high in countries with an aging population (9). For example, to date, $83 \%$ of deaths associated with COVID-19 in Italy were in patients $>70$ years (9), where the median age of patients with 2019-nCoV infection is 62 years, whilst the median age of patients who have died from COVID-19 is 78 years (9). In a Korean study, although the overall mortality rate was $0.9 \%$, the rate was $9.3 \%$ for individuals aged $\geq 80$ years (9). Similar results were reported in the United States. Some reports in China have indicated that most patients who have succumbed to the disease were $>80$ years $(9,13)$.

Studies have indicated that the virus may have first been transmitted through bats and may be a zoonotic disease $(14,15)$. Although it is a controllable disease, it has a medium to high transmissibility (16). This disease is mainly spread through the respiratory tract and human contact, but also through the fecal-oral route (17). Therefore, timely and effective control measures are warranted to prevent further transmission.

\section{Structural characteristics and possible binding receptors of 2019-nCoV}

In order to determine the genomic structural characteristics of 2019-nCoV, Ceraolo and Giorgi (18) collected 54 full genomic sequences of the virus. It was found that the genomes of these viruses and SARS species were highly similar through multiple alignment analysis. A large gene encoding a polyprotein, followed by four major structural proteins (including S, E, $\mathrm{M}$ and $\mathrm{N}$ proteins) and $\geq$ six other open reading frames (ORFs) related to viral assembly were found at the 5 ' end of the genome of these viruses $(18,19)$ (Fig. 1). Concurrently, they indicated that all sequenced 2019-nCoV genomes had a high degree of sequence identity (>99\%), whilst $96.2 \%$ of the sequence was most similar to bat coronavirus, which confirmed the concept of the zoonotic origin of 2019-nCoV (19). The RNA-dependent RNA polymerase and main protease (3C-like protein) of 2019-nCoV are critical to genomic replication and translation $(2,20)$. Among the four structural proteins, the $\mathrm{N}$ and $\mathrm{S}$ proteins are the most crucial. Studies have found that the $\mathrm{N}$ protein of 2019-nCoV has an almost $90 \%$ amino acid sequence identity with SARS-CoV (21). The N protein antibody of SARS-CoV may cross-react with 2019-nCoV, although there is no cross-immunization (21). Similar to SARS-CoV, the N protein of 2019-nCoV may play an important role in inhibiting RNA interference to resist host defense (21). Vankadari and Wilce (22) reported the homotrimeric structure of the 2019-nCoV S protein in closed (no ligand binding) and open (ligand binding) conformations. The $\mathrm{S}$ protein is a key protein of receptor binding (23). It undergoes a wide range of structural rearrangement to fuse the virus into the cell membrane of the host, and its affinity with receptor proteins of human cells is much higher than that of SARS-CoV (23). Therefore, it is considered to be involved in host cell adhesion and as a key target for vaccine development $(22,23)$. The specific adhesion process includes the binding of the virus $\mathrm{S} 1$ subunit to the host cell receptor to trigger the occurrence of trimer instability, which leads to the $\mathrm{S} 1$ subunit to detach from the S2 subunit to form a highly stable post-fusion structure (22). The $\mathrm{S}$ protein has a unique $N$ - and $O$-linked glycosylation site, which can be distinguished from SARS-CoV and plays a role in the protection and camouflaging of $2019-\mathrm{nCoV}$ to the host defense system (22). In addition, it was also found that the S1 region may be able to bind with human CD26 receptor, a key immune-regulatory factor, via van der Waals forces or hydrogen bonds (23). Their interaction induces T-cell activation by $\mathrm{CD} 26$, cleaving the amino terminal dipeptide for defense against COVID-19 (22). These findings may contribute to the development of novel therapies.

Early studies have confirmed that the human receptor for 2019-nCoV may be the ACE2 receptor, similar to SARS-CoV (24). Plasma ACE2 levels were shown to be significantly increased in patients with 2019-nCoV infection and are linearly associated with viral load and lung injury (25). ACE2 is widely distributed in a variety of tissues, including the heart, kidneys and testes, and plays an important role in controlling blood pressure and preventing heart failure and kidney injury (24). The loss of ACE2 in the lungs can enhance vascular permeability and pulmonary edema, resulting in severe lung injury (24). Therefore, the treatment of novel coronavirus with ACE2 as the target may be counterproductive and have negative effects. Recently, Wang et al (26) discovered a novel mechanism via which 2019-nCoV invades the host cell, where the S protein can bind to the receptor CD147 on the host cell, subsequently infecting the cell. This novel receptor provides an important 


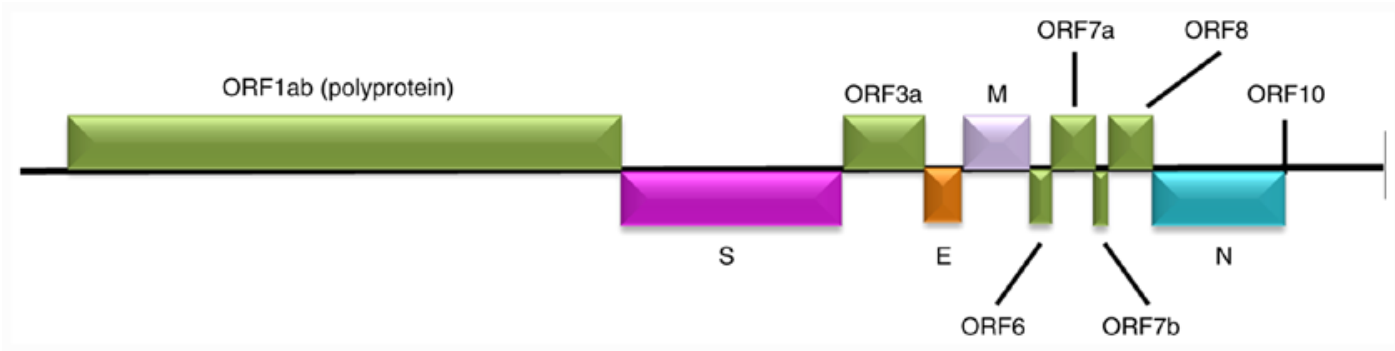

Figure 1. Location of the main structural protein and accessory protein ORFs for 2019-nCoV. S, spike protein; E, envelope protein; M, membrane protein; $\mathrm{N}$, nucleocapsid protein; ORFs, open reading frames.

direction for the discovery of specific and novel anti-coronavirus drugs (26).

\section{2019-nCoV-infected target cells}

Yao et al (27) demonstrated that in patients who succumbed to COVID-19, coronavirus particles were mainly distributed in the bronchial mucosal epithelium and type II alveolar epithelium of the lungs through electron microscopy observation. In addition, Zhao et al (28) revealed that $\sim 0.64 \%$ of human alveolar cells express ACE2, and 83\% of these cells are alveolar type 2 (AT2) cells. AT2 cells expressing ACE2 account for $\sim 1.4 \%$ of all AT2 cells. ACE2 is also expressed by other cells, such as alveolar type 1 cells, airway epithelial cells, fibroblasts, endothelial cells and macrophages (28). However, the proportion is very low and there is a marked difference among individuals (28). In patients infected with 2019-nCoV, the expression levels of numerous genes in AT2 cells expressing ACE2 are significantly increased (28). These genes are involved in viral replication, assembly and life cycle regulation (28). Moreover, Wang et al (29) found that alveolar macrophages expressing ACE2 are also the target cells of coronavirus infection, particularly in patients with severe and late advanced acute respiratory distress syndrome (ARDS), and macrophage injuries may be a critical cause of pulmonary inflammatory and fibrosis. Therefore, the lungs are the main target organs and AT2 cells and alveolar macrophages are the main target cells for $2019-\mathrm{nCoV}$ infection. In addition, 2019-nCoV can also cause kidney injury by targeting renal tubular epithelial cells (30), as well as damage to hepatocytes and bile duct epithelial cells $(31,32)$. In order for viruses to enter the cells in the body, they must find the corresponding receptor on human cells. Thus, each receptor functions as a 'lock', which requires a corresponding 'key' to be opened, where viruses can then enter the cell. The S protein of 2019-nCoV undergoes a variety of structural rearrangements to bind the virus to the receptor ACE2 and/or CD147 on host cells, leading to cell damage $(26,33)$. Therefore, the 'key' of $2019-\mathrm{nCoV}$ is the S protein, and the receptors ACE2 and CD147 on the host cell are the 'locks'.

\section{Clinical manifestations and complications of COVID-19}

It was reported that patients with underlying diseases, such as hypertension, respiratory diseases, diabetes and cardiovascular diseases, are at a greater risk of 2019-nCoV infection (34), and patients with previous cardiovascular or metabolic diseases are also at a greater risk of developing severe diseases, and this may have a marked impact on the prognosis of COVID-19 (35). The clinical characteristics of patients infected with 2019-nCoV are group onset and are more likely to infect older males (3). Its main clinical symptoms in the prodromal period include fever, dry cough, myalgia, fatigue and diarrhea, and a number of patients also have dyspnea (1), which can lead to severe and even fatal respiratory diseases (3). Fever and cough are the most common first symptoms which were reported in patients who have succumbed to the disease (36). In addition, Mao et al (37) observed that patients with 2019-nCoV also exhibit central nervous system symptoms, including agitation, rising body temperature, cramps in the hands and feet and even coma. Feng et al (38) found that patients with COVID-19 may have liver damage or dysfunction, mainly characterized by moderately elevated serum aspartate transaminase levels. Chen et al (39) also found that the conjunctival swab of COVID-19 contained 2019-nCoV, which led to conjunctival infection. Hedou et al (40) found that a small number of patients also have skin manifestations, such as morbilliform rash, urticaria and vesicles. Patients with COVID-19 may also present with acute kidney injury, and the mechanisms may be related to cell damage caused by $2019-\mathrm{nCoV}$ by targeting ACE2 on renal tubular epithelial cells (30). Complications of 2019-nCoV infection include ARDS, venous thromboembolism, acute heart injury and secondary infections $(1,3,41)$.

\section{Laboratory examinations, imaging and pathological features of COVID-19}

The most common laboratory abnormalities in patients with 2019-nCoV infection are hypoalbuminemia, lymphocytopenia, a decreased percentage of lymphocytes (LYM) and neutrophils (NEU), and increased C-reactive protein (CRP), interleukin-2 receptor (IL-2R), IL-6 and lactate dehydrogenase (LDH) levels (25). Moreover, levels of procalcitonin are typically normal, and high levels may indicate bacterial co-infection (42). The viral load of 2019-nCoV detected from the respiratory tract of patients is positively associated with the severity of pulmonary disease (43). In addition, albumin, LYM, LYM (\%), IL-2R, IL-6, alanine aminotransferase (ALT) and aspartate transaminase (AST) levels, prothrombin time, creatinine, D-dimer, creatine phosphokinase (CPK) levels, LDH, NEU (\%) and CRP levels are related to acute lung injury and the severity of the disease $(25,42,43)$. IgM and IgG antibodies can also be used as criteria for the diagnosis of the disease. IgM is more specific, while $\operatorname{IgG}$ is more 
sensitive (44). In most patients, arterial blood oxygen analysis yields abnormal results, usually manifested as a decrease in partial pressure of oxygen and an increase in partial pressure of carbon dioxide (45). Moreover, Ganji et al (46) found that the expression levels of CD8 in patients with COVID-19 were significantly higher compared with in healthy individuals; thus, the cellular immune response induced by COVID-19 infection may be generated by the overexpression of CD8 and the hyperactivation of cytotoxic $\mathrm{T}$ lymphocytes. In addition, reverse transcription-quantitative PCR (RT-qPCR) can also be used to detect the presence of the virus (47). The test samples are mainly obtained from the pharynx and blood, digestive tract, urine, and other body fluids, which also indicates that viral RNA can replicate outside the lungs $(48,49)$. Simultaneously, Corman et al (50) and Chan et al (51) verified that this method is highly sensitive and specific and can effectively distinguish 2019-nCoV from various other human respiratory viruses (including SARS-CoV) by detecting different segments of the virus. Currently, there is a higher accuracy of viral gene sequencing, which is also used in clinical practice (52). The two aforementioned methods are the most accurate methods to detect infection. However, in cases of lack of RT-qPCR reagents, certain hematological parameters, including the white blood cell count, CRP, AST, ALT and LDH, can also be used as a substitute for RT-qPCR to identify 2019-nCoV-positive patients by appropriate comparative analysis (52).

In terms of imaging, a chest CT scan is the first and most appropriate examination. In all reported cases, including asymptomatic patients, chest $\mathrm{CT}$ findings are abnormal and present with bilateral frosted glass shadows, while chest CT images of severe patients typically present with bilateral multiple lobules and sub-segmental consolidation (1).

It was found that the main reason for the mortality associated with COVID-19 is respiratory failure caused by severe lung injury and the failure of other vital organs (29). The organ with the most pathological changes is the lung (29). Tian et al (53) analyzed the pathology of two patients with adenocarcinoma infected with 2019-nCoV who recently underwent lobectomy. They found that, apart from the tumor, both patients had pulmonary edema, protein-like exudate, focal reactive pulmonary cell hyperplasia with plaque-like inflammatory cells and multicellular giant cell infiltration, as well as an inconspicuous transparent membrane. As neither patient exhibited symptoms of pneumonia during surgery, these changes may represent an early stage of the pulmonary pathology of COVID-19 (53). Subsequently, Yao et al (54) found significant pathological changes in the lungs during an autopsy of patients infected with COVID-19, including alveolar exudation and interstitial inflammation, alveolar epithelial proliferation and hyaline membrane formation. During the middle and late stages of infection with COVID-19, the lungs exhibit evident pathological changes, including alveolar exudative inflammation and interstitial inflammation, alveolar succulent alterations, alveolar epithelial hyperplasia and hyaline membrane formation (27,29). Wang et al (29) discovered that another feature of pathological changes was the retention of mucus secretions in the small airway, as well as the formation of mucus plug formation and the aggregation and activation of alveolar macrophages. Although $2019-\mathrm{nCoV}$ is mainly distributed in the lungs, the formation of clear thrombi in small blood vessels and the degeneration and necrosis of cells in the spleen, heart, liver and kidneys have also been observed (54). These changes are unique to COVID-19 compared with the previously reported SARS and MERS.

\section{Treatment of COVID-19}

At present, commonly used antiviral drugs in clinical practice, including neuraminidase inhibitors (oseltamivir, peramivir and zanamivir), ganciclovir, aciclovir and ribavirin, are ineffective and are therefore not recommended for 2019-nCoV (55). In treatment, drugs that inhibit viral spread and destroy viral replication, such as an anticoagulant, namely dipyridamole, may reduce the direct cytopathic effects induced by 2019-nCoV (56). In addition, high doses of vitamin D3 may be effective in individuals with COVID-19 by attenuating the rate of viral replication (57). A previous report found that cepharanthine (CEP), selamectin and mefloquine hydrochloride are potential drugs for the treatment of 2019-nCoV infection (58). CEP is a broad-spectrum $\beta$-RNA virus inhibitor, and it holds potential for the treatment of 2019-nCoV infections (58). Moreover, the main protease plays a key role in the replication and maturation of the virus and can be used as a major drug target (59). There are drugs that inhibit the main proteases of the coronavirus, such as histidine, piperidine E and folic acid, which bind tightly to the 3CL hydrolase enzyme, as potential therapeutic strategies (60). In addition, immunomodulatory or immunosuppressive treatments, such as anti-IL-6, anti-IL-6R, anti-IL-1 $\beta$, chloroquine and hydroxychloroquine inhibit the host inflammatory response by neutralizing the role of cytokines or their cognate receptors to further reduce immune response triggered by the virus $(3,61,62)$. Shetty $(63)$ found that the intravenous administration of human mesenchymal stem cells to patients with COVID-19 could be used as a therapeutic measure by improving the lung microenvironment following 2019-nCoV infection, suppressing the overactivation of the immune system, and promoting endogenous repair. Since 2019-nCoV binds to ACE in the host, it can be hypothesized that ACE inhibitors and angiotensin receptor blockers can be used in patients with COVID-19 under the condition of controlling blood pressure, which may reduce the pulmonary inflammatory response and mortality (64). Moreover, 2019-nCoV can also bind to CD147 in the host; thus, CD147 is also a potential target, although there is currently no drug available to target it $(26,65)$. Furthermore, for patients with severe coronavirus infection, hormone shock therapy such glucocorticoids can be used (66). The use of tissue plasminogen activators during rescue can improve the recovery of patients with ARDS, thus reducing the mortality rate associated with COVID-19 (67). Finally, venovenous extracorporeal membrane oxygenation is one of the ultimate treatments for acute respiratory failure caused by severe COVID-19 (68).

Moreover, controlling and eliminating the spread and reoccurrence of this pandemic demands a safe and effective vaccine strategy. At present, there are several different strategies available for the development of vaccine against 2019-nCoV worldwide. These methods include: i) Targeting the $\mathrm{S}$ protein of a main inducer of the immune response by 
using the full-length $\mathrm{S}$ protein, the binding domain of the $\mathrm{S} 1$ receptor, expressing the vector DNA of virus-like protein; ii) creating attenuated vaccines by pulling a mutation in the ORF1a/b polyprotein; iii) DNA vaccines to induce or enhance immune responses by resisting antigens of 2019-nCoV; iv) protein vaccines and v) virus-like particle vaccines (69). Although the use of vaccines is typically a more effective prevention strategy, however, they are currently still in development. Very few of these vaccines are currently in different phases of preclinical and clinical trials. This indicates that their effectiveness against 2019-nCoV has not yet been fully determined. Thus, the disease remains a high threat to human life.

\section{Conceptions}

Based on the aforementioned research reports and the characteristics of other viral infection cases, the following conceptions are proposed: i) At present, the search for and determination of viral receptors are all confirmed experiments due to the similarity of the 2019-nCoV and SARS-CoV sequence. However, considering the autopsy reports and electron microscopy observations, the viral number in alveolar epithelial cells expressing ACE2 receptors and CD147 is not consistent with the severity of disease. Thus, it is suggested that the $\mathrm{S}$ protein structure of 2019-nCoV should perhaps first be computationally stimulated to observe and analyze its binding ability with that of existing human cell receptors. Subsequently, molecular biology experiments can be used to verify and identify more effective receptors. This will lay a solid foundation for the preparation of neutralizing antibodies and the development of vaccines. It has also been confirmed that the CD147 receptor is highly expressed in a variety of tumors (66). Thus, it needs to be determined whether the fact that patients with basic tumor diseases are more susceptible to infection 2019-nCoV is closely related to the high expression of CD147 in tumors. This needs to be elucidated and supported by further research.

ii) The majority of severely affected patients are those with cardiovascular, respiratory and endocrine system diseases. It thus needs to be determined whether the metabolism and changes in parenchymal organ structure and function in these patients caused the aggravation of $2019-\mathrm{nCoV}$ infection and promoted the occurrence and development of the disease. However, this could be a serious illness caused by the poor tolerance of these patients to $2019-\mathrm{nCoV}$. This is also a question worthy of further consideration.

iii) Some patients with COVID-19 suffer from liver damage or dysfunction; however, the mechanisms responsible for this are not yet clear. It thus needs to be determined whether the liver cell damage is caused by viral infection or by the use of potential hepatotoxic drugs. This issue may prove to be a future topic of research.

iv) The activation of the immune response is the main source of different clinical symptoms in patients with 2019-nCoV infection. Therefore, whether treatment with novel peptide drugs that inhibit different immune signaling pathways can improve patient prognosis remains to be further verified by animal and clinical trials.

v) 2019-nCoV directly infects alveolar cells, although it does not directly damage them. Thus, it remains to be determined whether the virus alters the metabolic function of alveolar cells themselves or whether it modifies certain proteins of alveolar cells, rendering them foreign proteins, subsequently activating the body's immune system. It is also possible that viral proteins are expressed when they enter the body and directly activate immune cells, eventually leading to severe disease states. These are unanswered questions which require further investigation.

vi) At present, patient pharyngeal swab samples are mainly obtained, and viral nucleic acid is qualitatively detected by RT-qPCR to confirm infection. However, whether the therapeutic status and disease prognosis can be evaluated by detecting the content of 2019-nCoV-related antibodies remains to be further summarized and analyzed on existing clinical data.

\section{Conclusions and future prospects}

To date, no vaccine or specific antiviral drug has been developed for 2019-nCoV infections. Therefore, preventing the spread of the virus is the main intervention strategy to control infection. Two standard principles are very effective, namely the isolation of known cases and those with a high risk of exposure. Over the past few months, with the efforts of numerous countries worldwide, great progress has been made in pathogen surveillance, source determination, basic etiology, clinical treatment, drug testing and vaccine development. It is hoped that this pandemic will soon end. However, the emergence of this infectious disease is also a wake-up call. First, the origin of human pathogens should be reflected upon and humans should learn from this experience and reduce direct contact with wild animals. If humans continue to consume wild animals, the viruses carried by animals can have a devastating impact on humans, and the transition of these highly lethal viruses (such as SARS-CoV, MERS-CoV, H5N1, H7N9 and 2019-nCoV) from natural to human hosts will continue to occur, and may even escalate. Second, if early detection, early prevention and early isolation are adopted, the situation will not be extended to the whole country or even worldwide. Therefore, early detection, early reporting, early prevention and timely isolation of patients infected with $2019-\mathrm{nCoV}$ is mandatory, which may contribute to the elimination of the pandemic. Third, the identification of the main receptor and cells associated with 2019-nCoV invasion, and the investigation and elucidation of the direct and indirect mechanisms of 2019-nCoV, may greatly assist further vaccine research and development. In addition, it may also lead to the development of novel treatment strategies and measures with which to combat infection.

\section{Acknowledgements}

Not applicable.

\section{Funding}

The present study was supported by the National Natural Science Foundation of China (grant nos. 81600469, 81770607, 81772626), and the Major Special Plan of Science and Technology of Shandong Province (grant no. 2015ZDXX0802A01). 


\section{Availability of data and materials}

Not Applicable.

\section{Authors' contributions}

The conception or design of the work: JQ, XF and HB. The acquisition, analysis, or interpretation of data for the work: XF, XX, SS, WC, FR, HB and JQ. Critical revision for important intellectual content: QZ, WR, CQ and JQ. Approval of the final version to be published: All authors.

\section{Ethics approval and consent to participate}

Not applicable.

\section{Patient consent for publication}

Not applicable.

\section{Competing interests}

The authors declare that they have no competing interests.

\section{References}

1. Huang C, Wang Y, Li X, Ren L, Zhao J, Hu Y, Zhang L, Fan G Xu J, Gu X, et al: Clinical features of patients infected with 2019 novel coronavirus in Wuhan, China. Lancet 395: 497-506, 2020.

2. Calligari P, Bobone S, Ricci G and Bocedi A: Molecular investigation of SARS-CoV-2 proteins and their interactions with antiviral drugs. Viruses 12: 445, 2020.

3. Liu J, Zheng X, Tong Q, Li W, Wang B, Sutter K, Trilling M, Lu M, Dittmer U and Yang D: Overlapping and discrete aspects of the pathology and pathogenesis of the emerging human pathogenic coronaviruses SARS-CoV, MERS-CoV, and 2019-nCoV. J Med Virol 92: 491-494, 2020.

4. Zhu N, Zhang D, Wang W, Li X, Yang B, Song J, Zhao X, Huang B, Shi W, Lu R, et al: A novel coronavirus from patients with pneumonia in China, 2019. N Engl J Med 382: 727-733, 2020 .

5. Chu H, Chan JF, Wang Y, Yuen TT, Chai Y, Hou Y, Shuai H, Yang D, Hu B, Huang X, et al: Comparative replication and immune activation profiles of SARS-CoV-2 and SARS-CoV in human lungs: An ex vivo study with implications for the pathogenesis of COVID-19. Clin Infect Dis 71: 1400-1409, 2020.

6. Ammad Ud Din M and Boppana LK: An update on the 2019-nCoV outbreak. Am J Infect Control 48: 713, 2020.

7. National Health Commission of the People's Republic of China http://www.nhc.gov.cn/. Accessed November, 2020.

8. Johns Hopkins University and Medicine. https://coronavirus.jhu. edu/map.html. Accessed November, 2020.

9. Bulut C and Kato Y: Epidemiology of COVID-19. Turk J Med Sci 50: 563-570, 2020.

10. Cai H: Sex difference and smoking predisposition in patients with COVID-19. Lancet Respir Med 8: e20, 2020.

11. Gebhard C, Regitz-Zagrosek V, Neuhauser HK, Morgan R and Klein SL: Impact of sex and gender on COVID-19 outcomes in Europe. Biol Sex Differ 11: 29, 2020.

12. La Vignera S, Cannarella R, Condorelli RA, Torre F, Aversa A and Calogero AE: Sex-specific SARS-CoV-2 mortality: Among hormone-modulated ACE2 expression, risk of venous thromboembolism and hypovitaminosis D. Int J Mol Sci 21: 2948, 2020.

13. Wang Y, Wang Y, Chen Y and Qin Q: Unique epidemiological and clinical features of the emerging 2019 novel coronavirus pneumonia (COVID-19) implicate special control measures. J Med Virol 92: 568-576, 2020.

14. Benvenuto D, Giovanetti M, Ciccozzi A, Spoto S, Angeletti S and Ciccozzi M: The 2019-new coronavirus epidemic: Evidence for virus evolution. J Med Virol 92: 455-459, 2020.
15. Salata C, Calistri A, Parolin C and Palu G: Coronaviruses: A paradigm of new emerging zoonotic diseases. Pathog Dis 77: ftaa006, 2019.

16. Chen J: Pathogenicity and transmissibility of 2019-nCoV-A quick overview and comparison with other emerging viruses. Microbes Infect 22: 69-71, 2020.

17. Zhang W, Du RH, Li B, Zheng XS, Yang XL, Hu B, Wang YY, Xiao GF, Yan B, Shi ZL and Zhou P: Molecular and serological investigation of 2019-nCoV infected patients: Implication of multiple shedding routes. Emerg Microbes Infect 9: 386-389, 2020.

18. Ceraolo C and Giorgi FM: Genomic variance of the 2019-nCoV coronavirus. J Med Virol 92: 522-528, 2020.

19. Baruah V and Bose S: Immunoinformatics-aided identification of $\mathrm{T}$ cell and $\mathrm{B}$ cell epitopes in the surface glycoprotein of 2019-nCoV. J Med Virol 92: 495-500, 2020.

20. Morse JS, Lalonde T, Xu S and Liu WR: Learning from the Past: Possible urgent prevention and treatment options for severe acute respiratory infections caused by $2019-\mathrm{nCoV}$. Chembiochem 21: $730-738,2020$.

21. Kannan S, Shaik Syed Ali P, Sheeza A and Hemalatha K: COVID-19 (Novel Coronavirus 2019)-recent trends. Eur Rev Med Pharmacol Sci 24: 2006-2011, 2020.

22. Vankadari N and Wilce JA: Emerging WuHan (COVID-19) coronavirus: Glycan shield and structure prediction of spike glycoprotein and its interaction with human CD26. Emerg Microbes Infect 9: 601-604, 2020.

23. Kumar S, Maurya VK, Prasad AK, Bhatt MLB and Saxena SK: Structural, glycosylation and antigenic variation between 2019 novel coronavirus (2019-nCoV) and SARS coronavirus (SARS-CoV). Virusdisease 31: 13-21, 2020.

24. Lu R, Zhao X, Li J, Niu P, Yang B, Wu H, Wang W, Song H, Huang B, Zhu N, et al: Genomic characterisation and epidemiology of 2019 novel coronavirus: Implications for virus origins and receptor binding. Lancet 395: 565-574, 2020.

25. Liu Y, Yang Y, Zhang C, Huang F, Wang F, Yuan J, Wang Z, Li J, Li J, Feng C, et al: Clinical and biochemical indexes from 2019-nCoV infected patients linked to viral loads and lung injury. Sci China Life Sci 63: 364-374, 2020.

26. Wang K, Chen W, Zhou YS, Lian JQ, Zhang Z, Du P, Gong L, Zhang Y, Cui HY, Geng JJ, et al: SARS-CoV-2 invades host cells via a novel route: CD147-spike protein. bioRxiv: Mar 14, 2020 (Epub ahead of print). doi: https://doi. org/10.1101/2020.03.14.988345.

27. Yao XH, Li TY, He ZC, Ping YF, Liu HW, Yu SC, Mou HM, Wang LH, Zhang HR, Fu WJ, et al: A pathological report of three COVID-19 cases by minimally invasive autopsies. Zhonghua Bing Li Xue Za Zhi 49: 411-417, 2020 (In Chinese).

28. Zhao Y, Zhao Z, Wang Y, Zhou Y, Ma Y and Zuo W: Single-cell RNA expression profiling of ACE2, the putative receptor of Wuhan 2019-nCoV. bioRxiv: Jan 26, 2020 (Epub ahead of print). doi: https://doi.org/10.1101/2020.01.26.919985.

29. Wang C, Xie J, Zhao L, Fei X, Zhang H, Tan Y, Zhou L, Liu Z Ren Y, Yuan L, et al: Aveolar macrophage activation and cytokine storm in the pathogenesis of severe COVID-19. Res Square: Mar 25, 2020 (Epub ahead of print). doi: https://doi. org/10.21203/rs.3.rs-19346/v1.

30. Angel-Korman A, Brosh T, Glick K and Leiba A: COVID-19, the kidney and hypertension. Harefuah 159: 231-234, 2020.

31. Chai X, Hu L, Zhang Y, Han W, Lu Z, Ke A, Zhou J, Shi G, Fang N, Fan J, et al: Specific ACE2 expression in cholangiocytes may cause liver damage after 2019-nCoV infection. bioRxiv: Feb 4, 2020 (Epub ahead of print). doi: 10.1101/2020.02.03.931766.

32. Guan GW, Gao L, Wang JW, Wen XJ, Mao TH, Peng SW, Zhang T, Chen XM and Lu FM: Exploring the mechanism of liver enzyme abnormalities in patients with novel coronavirus-infected pneumonia. Zhonghua Gan Zang Bing Za Zhi 28: 100-106, 2020 (In Chinese)

33. Hoffmann M, Kleine-Weber H, Schroeder S, Krüger N, Herrler T, Erichsen S, Schiergens TS, Herrler G, Wu NH, Nitsche A, et al: SARS-CoV-2 cell entry depends on ACE2 and TMPRSS2 and is blocked by a clinically proven protease inhibitor. Cell 181: 271-280.e8, 2020.

34. Yang J, Zheng Y, Gou X, Pu K, Chen Z, Guo Q, Ji R, Wang H, Wang Y and Zhou Y: Prevalence of comorbidities in the novel Wuhan coronavirus (COVID-19) infection: A systematic review and meta-analysis. Int J Infect Dis 94: 91-95, 2020.

35. Li B, Yang J, Zhao F, Zhi L, Wang X, Liu L, Bi Z and Zhao Y: Prevalence and impact of cardiovascular metabolic diseases on COVID-19 in China. Clin Res Cardiol 109: 531-538, 2020. 
36. Wang W, Tang $\mathbf{J}$ and Wei F: Updated understanding of the outbreak of 2019 novel coronavirus $(2019-\mathrm{nCoV})$ in Wuhan, China. J Med Virol 92: 441-447, 2020.

37. Mao L, Jin H, Wang M, Hu Y, Chen S, He Q, Chang J, Hong C, Zhou Y, Wang D, et al: Neurologic manifestations of hospitalized patients with coronavirus disease 2019 in Wuhan, China. JAMA Neurol 77: 683-690, 2020.

38. Feng G, Zheng KI, Yan QQ, Rios RS, Targher G, Byrne CD, Poucke SV, Liu WY and Zheng MH: COVID-19 and liver dysfunction: Current insights and emergent therapeutic strategies. J Clin Transl Hepatol 8: 18-24, 2020.

39. Chen L, Liu M, Zhang Z, Qiao K, Huang T, Chen M, Xin N, Huang Z, Liu L, Zhang G and Wang J: Ocular manifestations of a hospitalised patient with confirmed 2019 novel coronavirus disease. Br J Ophthalmol 104: 748-751, 2020

40. Hedou M, Carsuzaa F, Chary E, Hainaut E, Cazenave-Roblot F and Masson Regnault M: Comment on 'Cutaneous manifestations in COVID-19: A first perspective' by Recalcati S. J Eur Acad Dermatol Venereol 34: e299-e300, 2020.

41. Cui S, Chen S, Li X, Liu S and Wang F: Prevalence of venous thromboembolism in patients with severe novel coronavirus pneumonia. J Thromb Haemost 18: 1421-1424, 2020.

42. Singhal T: A review of coronavirus disease-2019 (COVID-19). Indian J Pediatr 87: 281-286, 2020.

43. Chen L, Liu HG, Liu W, Liu J, Liu K, Shang J, Deng Y and Wei S: Analysis of clinical features of 29 patients with 2019 novel coronavirus pneumonia. Zhonghua Jie $\mathrm{He} \mathrm{He} \mathrm{Hu} \mathrm{Xi} \mathrm{Za}$ Zhi 43 : 203-208, 2020 (In Chinese).

44. Jin Y, Wang M, Zuo Z, Fan C, Ye F, Cai Z, Wang Y, Cui H, Pan K and $\mathrm{Xu} \mathrm{A}$ : Diagnostic value and dynamic variance of serum antibody in coronavirus disease 2019. Int J Infect Dis 94: 49-52, 2020.

45. Tobin MJ: Basing respiratory management of COVID-19 on physiological principles. Am J Respir Crit Care Med 201: 1319-1320, 2020.

46. Ganji A, Farahani I, Khansarinejad B, Ghazavi A and Mosayebi G: Increased expression of CD8 marker on T-cells in COVID-19 patients. Blood Cells Mol Dis 83: 102437, 2020.

47. Chu DKW, Pan Y, Cheng SMS, Hui KPY, Krishnan P, Liu Y, Ng DYM, Wan CKC, Yang P, Wang Q, et al: Molecular diagnosis of a novel coronavirus (2019-nCoV) causing an outbreak of pneumonia. Clin Chem 66: 549-555, 2020.

48. Chen W, Lan Y, Yuan X, Deng X, Li Y, Cai X, Li L, He R, Tan Y, Deng X, et al: Detectable 2019-nCoV viral RNA in blood is a strong indicator for the further clinical severity. Emerg Microbes Infect 9: 469-473, 2020

49. Peng L, Liu J, Xu W, Luo Q, Chen D, Lei Z, Huang Z, Li X, Deng K, Lin B and Gao Z: SARS-CoV-2 can be detected in urine, blood, anal swabs, and oropharyngeal swabs specimens. J Med Virol, Apr 24, 2020 (Online ahead of print).

50. Corman VM, Landt O, Kaiser M, Molenkamp R, Meijer A, Chu DK, Bleicker T, Brünink S, Schneider J, Schmidt ML, et al: Detection of 2019 novel coronavirus $(2019-\mathrm{nCoV})$ by real-time RT-PCR. Euro Surveill 25: 2000045, 2020.

51. Chan JF, Yip CC, To KK, Tang TH, Wong SC, Leung KH, Fung AY, Ng AC, Zou Z, Tsoi HW, et al: Improved molecular diagnosis of COVID-19 by the novel, highly sensitive and specific COVID-19-RdRp/Hel Real-time reverse transcription-PCR assay validated in vitro and with clinical specimens. J Clin Microbiol 58: e00310-20, 2020.

52. Ferrari D, Motta A, Strollo M, Banfi G and Locatelli M: Routine blood tests as a potential diagnostic tool for COVID-19. Clin Chem Lab Med 58: 1095-1099, 2020.

53. Tian S, Hu W, Niu L, Liu H, Xu H and Xiao SY: Pulmonary pathology of early-phase 2019 novel coronavirus (COVID-19) pneumonia in two patients with lung cancer. J Thorac Oncol 15: $700-704,2020$

54. Yao XH, Li TY, He ZC, Ping YF, Liu HW, Yu SC, Mou HM, Wang LH, Zhang HR, Fu WJ, et al: A pathological report of three COVID-19 cases by minimal invasive autopsies. Zhonghua Bing Li Xue Za Zhi 49: 411-417, 2020 (In Chinese).
55. Li H, Wang YM, Xu JY and Cao B: Potential antiviral therapeutics for 2019 novel coronavirus. Zhonghua Jie $\mathrm{He} \mathrm{He} \mathrm{Hu} \mathrm{Xi} \mathrm{Za}$ Zhi 43: 170-172, 2020 (In Chinese).

56. Liu X, Li Z, Liu S, Sun J, Chen Z, Jiang M, Zhang Q, Wei Y, Wang X, Huang YY, et al: Potential therapeutic effects of dipyridamole in the severely ill patients with COVID-19. Acta Pharm Sin B 10: 1205-1215, 2020.

57. Grant WB, Lahore H, McDonnell SL, Baggerly CA, French CB Aliano JL and Bhattoa HP: Evidence that vitamin D supplementation could reduce risk of influenza and COVID-19 infections and deaths. Nutrients 12: 988, 2020.

58. Fan HH, Wang LQ, Liu WL, An XP, Liu ZD, He XQ, Song LH and Tong YG: Repurposing of clinically approved drugs for treatment of coronavirus disease 2019 in a 2019-novel coronavirus-related coronavirus model. Chin Med J (Engl) 133: 1051-1056, 2020.

59. Joshi RS, Jagdale SS, Bansode SB, Shankar SS, Tellis MB, Pandya VK, Chugh A, Giri AP and Kulkarni MJ: Discovery of potential multi-target-directed ligands by targeting host-specific SARS-CoV-2 structurally conserved main protease. J Biomol Struct Dyn: May 5, 2020 (Epub ahead of print). doi: 10.1080/073 91102.2020 .1760137

60. Serseg T, Benarous K and Yousfi M: Hispidin and Lepidine E: Two natural compounds and folic acid as potential inhibitors of 2019-novel coronavirus main protease (2019-nCoVMpro), molecular docking and SAR study. Curr Comput Aided Drug Des: Apr 21, 2020 (Epub ahead of print).

61. Abena PM, Decloedt EH, Bottieau E, Suleman F, Adejumo P, Sam-Agudu NA, Muyembe TamFum JJ, Seydi M, Eholie SP, Mills EJ, et al: Chloroquine and hydroxychloroquine for the prevention or treatment of COVID-19 in Africa: Caution for inappropriate off-label use in healthcare settings. Am J Trop Med Hyg 102: 1184-1188, 2020.

62. Tufan A, Avanoğlu Güler A and Matucci-Cerinic M: COVID-19, immune system response, hyperinflammation and repurposing antirheumatic drugs. Turk J Med Sci 50: 620-632, 2020.

63. Shetty AK: Mesenchymal stem cell infusion shows promise for combating coronavirus (COVID-19)-induced pneumonia. Aging Dis 11: 462-464, 2020.

64. Sun ML, Yang JM, Sun YP and Su GH: Inhibitors of RAS might be a good choice for the therapy of COVID-19 pneumonia. Zhonghua Jie He He Hu Xi Za Zhi 43: 219-222, 2020 (In Chinese).

65. Kong LM, Liao CG, Zhang Y, Xu J, Li Y, Huang W, Zhang Y, Bian $\mathrm{H}$ and Chen $\mathrm{ZN}$ : A regulatory loop involving miR-22, Sp1, and c-Myc modulates CD147 expression in breast cancer invasion and metastasis. Cancer Res 74: 3764-3778, 2014.

66. Qin YY, Zhou YH, Lu YQ, Sun F, Yang S, Harypursat V and Chen YK: Effectiveness of glucocorticoid therapy in patients with severe coronavirus disease 2019: Protocol of a randomized controlled trial. Chin Med J (Engl) 133: 1080-1086, 2020.

67. Choudhury R, Barrett CD, Moore HB, Moore EE, McIntyre RC, Moore PK, Talmor DS, Nydam TL and Yaffe MB: Salvage use of tissue plasminogen activator (tPA) in the setting of acute respiratory distress syndrome (ARDS) due to COVID-19 in the USA: A Markov decision analysis. World J Emerg Surg 15: 29, 2020.

68. Taniguchi H, Ogawa F, Honzawa H, Yamaguchi K, Niida S, Shinohara M, Takahashi K, Iwashita M, Abe T, Kubo S, et al: Veno-venous extracorporeal membrane oxygenation for severe pneumonia: COVID-19 case in Japan. Acute Med Surg 7: e509, 2020.

69. Omolo CA, Soni N, Fasiku VO, Mackraj I and Govender T: Update on therapeutic approaches and emerging therapies for SARS-CoV-2 virus. Eur J Pharmacol 883: 173348, 2020.

(i) $\Theta$ This work is licensed under a Creative Commons Attribution-NonCommercial-NoDerivatives 4.0 International (CC BY-NC-ND 4.0) License. 